Note: This document differs in layout from the original article which was published in Ichnos 2: 277-290 (1993)

(for more information about the journal see http://www.tandf.co.uk/journals/titles/10420940.html)

\title{
Decapod burrows in mangrove-channel and back-reef environments at the Atlantic Barrier Reef, Belize
}

\author{
Peter C. Dworschak and Jörg A. Ott \\ Institut für Zoologie der Universität Wien, Althanstraße 14, A-1090 Wien, Austria
}

\begin{abstract}
Burrows of decapod crustaceans were investigated by in situ resin casting in various mangrove and back-reef environments. Alpheid shrimps (A. floridanus and A. heterochaelis) were the most numerous burrowing shrimps in soft muddy sediments of mangrove channels. Their burrows consist either of a single $U$ or a series of U's inhabited by a pair of shrimp or are $\mathrm{Y}$-shaped and inhabited by a single shrimp and a gobiid associate. Large mounds and deep funnels are produced by the thalassinidean Glypturus acanthochirus, both in bare sediments of mangrove channels and in back-reef subtidal sediments. Their burrows consist of a spiral with several radiating branches leading to the surface and deeper blind chambers often filled with shell particles reaching to a depth of over $160 \mathrm{~cm}$. The thalassinidean Neocallichirus grandimana inhabits the intertidal of protected back-reef sands; it occupies shallow, mainly horizontal burrows. Corallianassa longiventris, characteristic of coarse sediments of the intertidal and shallow subtidal back-reef, inhabits simple J- to U-shaped burrows with blindly ending chambers in 60 to $80 \mathrm{~cm}$ sediment depth. Axiopsis serratifrons lives in pairs in sediments with a higher content of coral rubble; its burrows are simple, inclined, and spiral-shaped and reach a sediment depth of $30 \mathrm{~cm}$.

All burrows described in this paper are similar to those previously recorded for the respective species. Only the burrows of alpheids are less deep than those described from the intertidal. The burrowing activity of $G$. acanthochirus greatly influences grain size distribution and accumulation of large shell particles in deeper sediment layers. Burrow types reflect the systematic group to which the animals belong rather than feeding modes.
\end{abstract}

Key Words: burrows, Caribbean, Decapoda, mangrove, back-reef, bioturbation

\section{Introduction}

Lebensspuren of tropical environments have been well documented by resin casting (e.g. Shinn, 1968; Farrow, 1971; Braithwaite \& Talbot, 1972; Suchanek, 1986; Vaugelas, 1986, 1990) in back-reef and reef-lagoonal environments. Burrowing animals in mangrove communities have received only little attention in earlier reviews of this biotope (e.g. Verwey, 1929; Gerlach, 1958; Macnae, 1968). More recent ecological studies mainly deal with burrowing crabs from the intertidal (Dye and Lasiak, 1986; Robertson, 1986; Warren and Underwood, 1986; Macintosh, 1988; Robertson and Daniel, 1989; Micheli et al., 1991; Smith et al., 1991). Burrow construction and maintenance, ventilation and import of organic matter may play a significant role in the energy flow and element cycling in shallow coastal systems (for a review with respect to tropical ecosystems see Alongi, 1989). The tidal channels within mangrove systems are sites of high nutrient concentrations, benthic and pelagic primary production and microbial and animal secondary production (Herndl, 1991 and references cited in Alongi, 1989). At the same time their bottoms may be heavily burrowed by crustaceans. Such a situation was studied in the mangrove island Twin Cays, which is situated close to the Smithsonian Institution Field Station at Carrie Bow Cay, Belize. The aim of this contribution is to provide an inventory of burrowers and burrow types as well as an estimation of their density in mangrove and back-reef environments. In addition, observations on behavior and activity are reported.

\section{Study Sites}

Investigations were carried out at five different sites at the Belize Barrier Reef (for details see Rützler \& Macin-tyre, 1982)(Fig.1). At Twin Cays, (1) in "Cassiopea Cove", a bay of East Cay at the northern end of the Main Channel. The sediment bottom in 0.5 to 2 $\mathrm{m}$ depth is a soft, muddy, medium to fine sand with a median diameter between 94 and $268 \mu \mathrm{m}$, a subsieve fraction $(<63 \mu \mathrm{m})$ between 17 and 33\%, and an organic content between 5.4 and $9.7 \%$ (loss on ignition at $450^{\circ}$ for $4 \mathrm{~h}$ ). It is covered with a sparse vegetation of Penicillus capitatus and Halimeda sp. and is characterized by large mounds and funnels. Numerous specimens (up to $5 \mathrm{~m}^{-2}$ ) of the upside-down jellyfish Cassiopea xamachana lie on the bottom (Fig. 2 A); (2) at a station at the south end of the Main Channel characterized by soft mud densely covered by Thalassia testudinum (Fig. 2 B); (3) at a station at the entrance of the Main Channel to the south which is characterized by firm medium sand with a median diameter between 267 and $426 \mu \mathrm{m}$, a subsieve fraction between 9 and $21 \%$, an organic content between 3.9 and $4.6 \%$, and a cover of short-leaved Thalassia and patches of Halodule; (4) at 


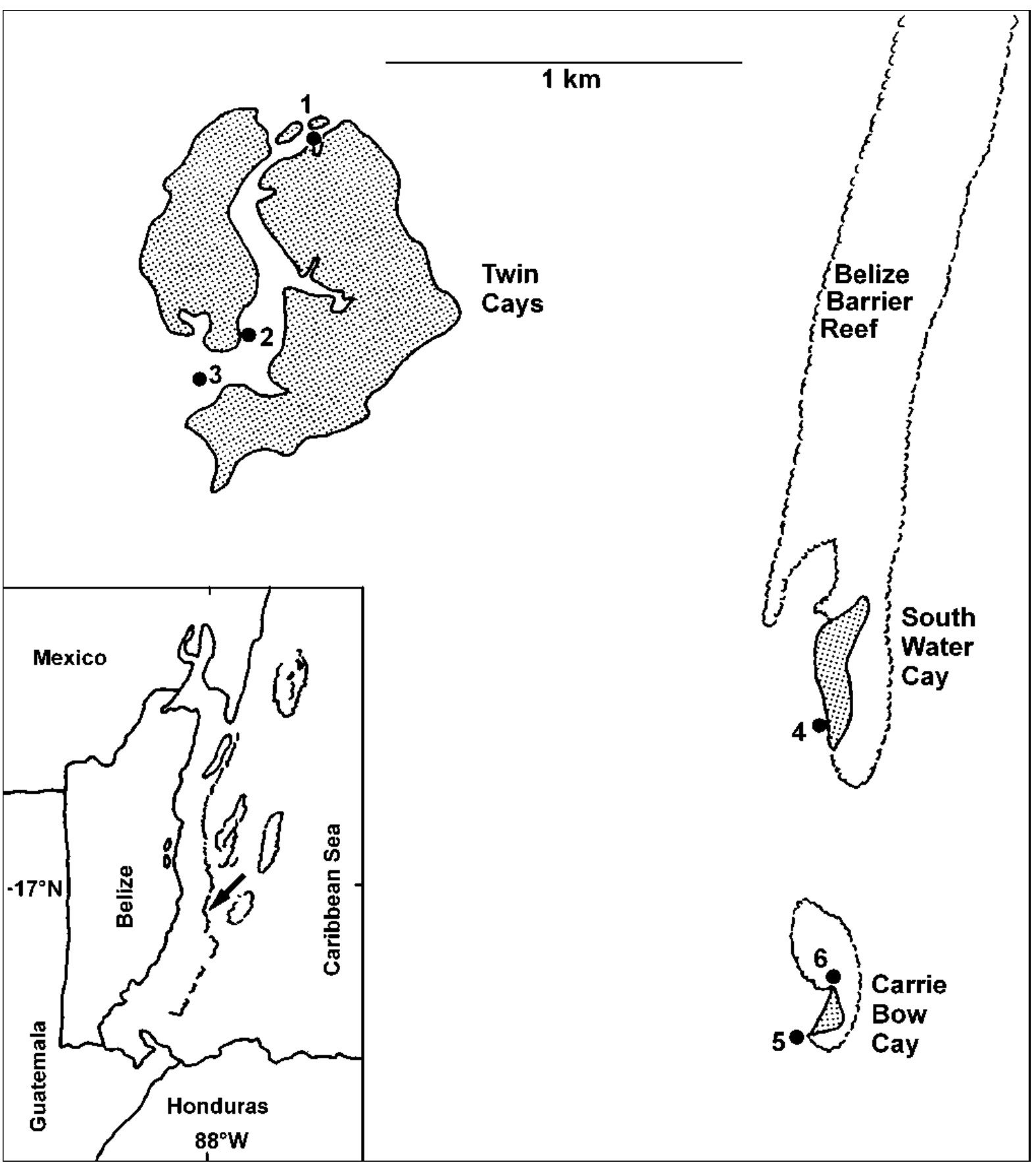

Fig. 1. Study sites (arrow in insert) at the Central America Barrier Reef, Belize. Twin Cays: 1) "Cassiopea Cove", 2) station in Main Channel, 3) entrance of Main Channel; South Water Cay: 4) broken landing at lagoonside; Carrie Bow Cay: 5) north of "Garbage Reef", 6) "North End Sand Bar".

the lagoonside of South Water Cay. The sediment in the intertidal is a coarse sand with a median diameter of 683 to $707 \mu \mathrm{m}$, a subsieve fraction between 2.9 and $4 \%$, and an organic content between 3.3 and $3.5 \%$. At 0.5 to $1 \mathrm{~m}$ water depth, the sediment is a coarse sand with a median diameter between 536 and $637 \mu \mathrm{m}$, a subsieve fraction between 5.2 and $5.8 \%$, and an organic content between 1.2 and $1.4 \%$; it is characterized by numerous mounds and funnels; (5) at the lagoonside of Carrie Bow Cay south near "Garbage Reef" (Fig.2 C); and (6) near the 

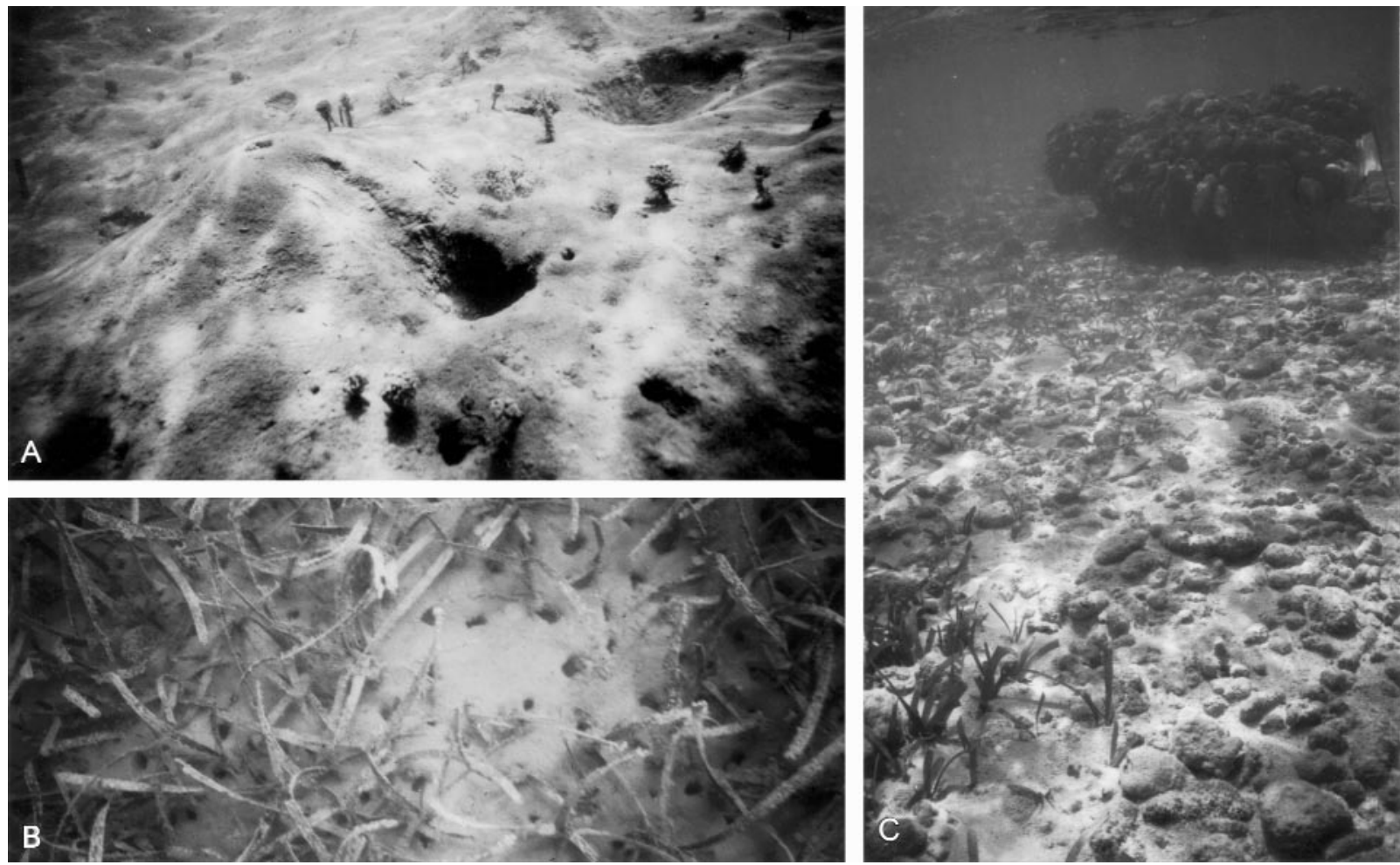

Fig. 2. A) Surface aspect at "Cassiopea Cove"; mounds and funnels produced by Glypturus acanthochirus, burrow openings of Alpheus spp., Penicillus capitatus, and Cassiopea xamancha (water depth $2 \mathrm{~m}$, distance across base is $1.2 \mathrm{~m}$ )(Photo: M. Parrish); B) surface aspect at the station in Main Channel, burrow openings of Alpheus spp. in soft mud between Thalassia (water depth $3.5 \mathrm{~m}$, area is $105 \times 45 \mathrm{~cm}$ ). C) Rubble field at Carrie Bow Cay near "Garbage Reef", site of Axiopsis serratifrons and Corallianassa longiventris (water depth $1.5 \mathrm{~m}$, coral head in background is approx. $1.5 \mathrm{~m}$ in diameter).

"North End Sandbar", where the sediment is a coarse sand with a median diameter of $1 \mathrm{~mm}$ and a subsieve fraction below $0.1 \%$ (Ott and Novak, 1989).

The mean tidal range is $15 \mathrm{~cm}$ (Kjerfve et al., 1982), water temperature in channels at Twin Cays range from $18.2^{\circ}$ (February 1990) to $35.0^{\circ}$ (August 1989)(Rützler, pers. comm.).

\section{Methods}

Burrows were studied by in situ resin casting using an epoxy resin (for details see Pervesler and Dworschak, 1985) in November 1987 and June 1989 at stations (1) to (5) and May 1988 at site (6). Burrowing shrimp were captured either with an air-lift sampler similar to that described by Thomassin (1978), with a "yabby pump" similar to that described by Manning (1975), or by means of "weighted lines" (Vaugelas, 1985). For reference, preserved specimens were deposited in the National Museum of Natural History (Washington), the Muséum National d'Histoire Naturelle (Paris), and the Naturhistorisches Museum (Wien).
Surface features were documented by underwater photographs using a Nikonos III and V equipped with $15 \mathrm{~mm}, 28 \mathrm{~mm}$ or close-up lens. The density of burrow openings and mounds was determined by photographing the bottom along a transect at position (1); here, burrow dynamics were documented by photographing 3 marked square meters daily over a period of 10 days. Sediment core (acrylic-glass tube with an inner diameter of $3 \mathrm{~cm}$ ) samples were analyzed as outlined by Buchanan (1984).

In the laboratory, the behavior of the burrowing crustaceans was observed in narrow aquaria $(24 \times 36 \times 3$ $\mathrm{cm}$ ) filled with natural sediment.

\section{Results}

\section{Alpheus heterochaelis Say and A. floridanus}

\section{Kingsley}

The most abundant burrowing crustaceans in Cassiopea Cove sediments as well as in the Main Channel (station 2) are alpheid shrimps. In Cassiopea Cove, up to 20 holes per square meter can be attributed to burrows of these 
shrimp. Air-lift sampling yielded 1-4 shrimps per $0.1 \mathrm{~m}^{2}$. At station 2, 70 holes per $\mathrm{m}^{2}$ were counted (Fig. $3 \mathrm{~B}$ ).

Resin casting shows that two different types of burrows exist. The first are small and consist of a single $\mathrm{U}$ (5-6 cm deep, $6 \mathrm{~cm}$ in horizontal extension)(Fig. $3 \mathrm{~A}$ ) or several U-shaped parts (up to $15-20 \mathrm{~cm}$ deep, $50 \mathrm{~cm}$ horizontal extension)(Fig. 3 B). Especially at station 2 these burrows consist of numerous U- shaped portions, resulting in up to 8 burrow openings per burrow. The smaller burrows seem to be inhabited by a single shrimp or a pair of shrimp. On the surface these burrows have simple or slit-shaped $(15-17 \times 17-25 \mathrm{~mm})$ openings, which often occur in groups of 3 to 5 openings, each 3 to $5 \mathrm{~cm}$ apart. The burrow wall is smooth.

The second type are large burrows - $30 \mathrm{~cm}$ deep and up to $73 \mathrm{~cm}$ in horizontal extension. They are characterized on the surface by funnel-shaped openings (up to $10 \mathrm{~cm}$ in diameter) with sediment piles surrounding it (Fig. $3 \mathrm{C}$ ). They are inhabited by a shrimp together with a gobiid fish. The gobiid associate (so far 3 unidentified species) can often been seen together with its host near the entrance. The walls of these burrows are very rough and irregular.

Two species could be identified, Alpheus floridanus and Alpheus heterochaelis. Of the specimens from 1987, nine belonged to A. floridanus (3 males, 6 females (5 of them ovigerous) and 1 to A. heterochaelis. Entombed in resin casts were one A. heterochaelis and three A. floridanus. A. floridanus occasionally fled while their burrow was being filled with resin and were often consumed by fishes before they could be collected by hand. The cast containing the A. heterochaelis specimen is similar in shape to those of A. floridanus (Fig. $3 \mathrm{D}$ ). The size of the animals ranged from 27 to $47 \mathrm{~mm}$ total length. Burrow diameter is relatively large compared to the size of the animals, e.g. the burrow shown in Fig. 3 A (elliptical cross-section $25 \times 46 \mathrm{~mm}$ ) was inhabited by a 27 $\mathrm{mm}$ long shrimp.

\section{Axiopsis serratifrons (A. Milne Edwards)}

Burrow openings of Axiopsis serratifrons can be found all around Carrie Bow Cay in coral rubble with sand at a water depth between 0.5 and $1.5 \mathrm{~m}$. Usually, the density does not exceed 1 burrow $\mathrm{m}^{-2}$. The burrow opening is irregular $(3-5 \times 2-3 \mathrm{~cm})$ and is often surrounded by large pieces of rubble (Fig. 4 A). Sometimes, a second opening is present under pieces of coral rubble a few $\mathrm{cm}$ away. The black shrimp can frequently be seen near the opening and can be baited with seagrass, which it tries to pull into its burrow. A polyester resin cast made in 1987 (Fig. $4 \mathrm{~B}$ ) shows the burrow to be simple inclined spiral reaching to a total depth of $30 \mathrm{~cm}$ with several chambers $(40 \times$ $80 \mathrm{~mm}$ in diameter) at different depths. Shaft segments between chambers have an irregular cross-section and measure between 19 and $24 \mathrm{~mm}$ in diameter. Pieces of rubble are attached to the resin at chamber floors, whereas the roofs are smooth. Seagrass blades were

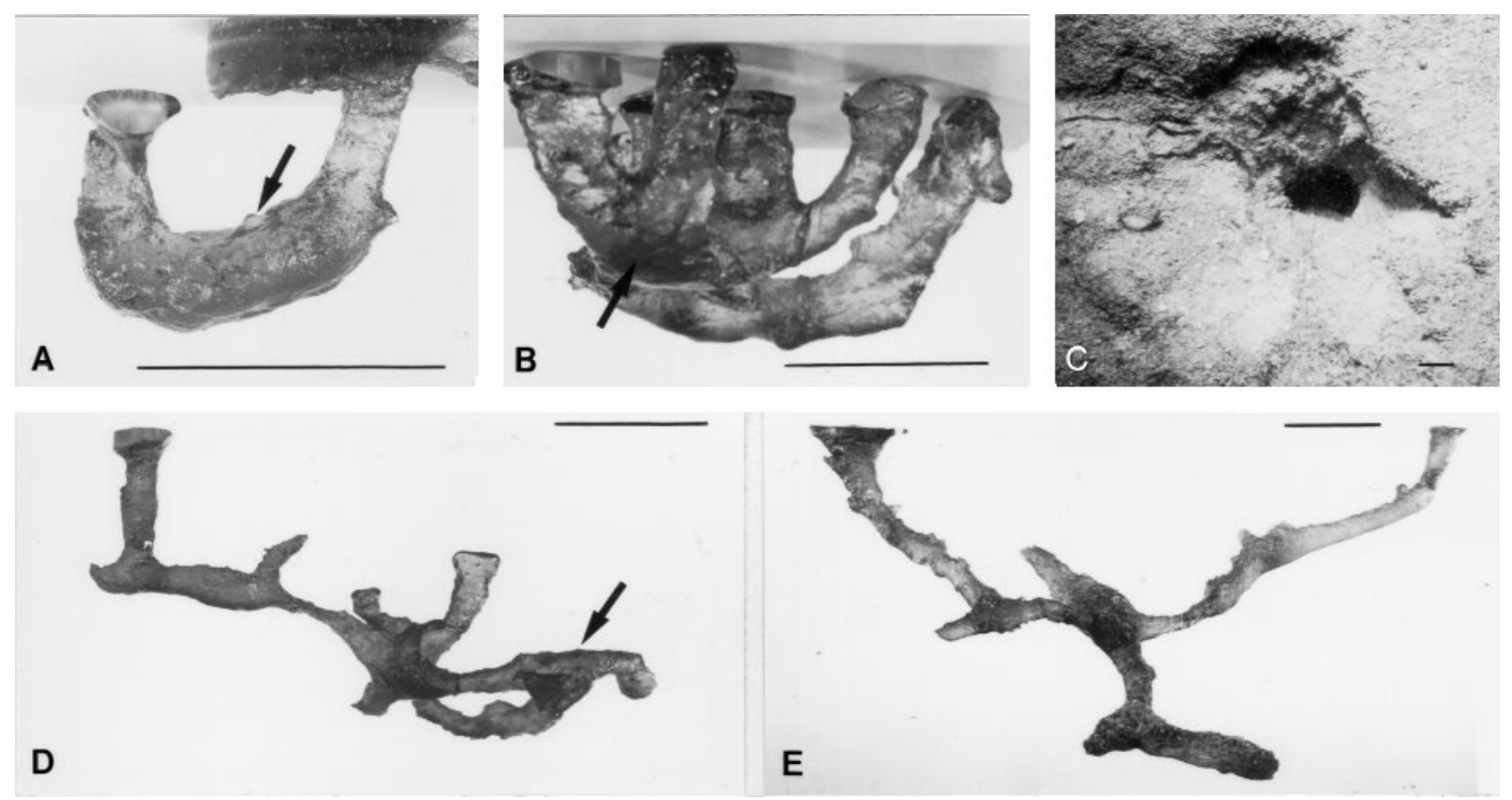

Fig. 3. Burrows of Alpheus spp., Twin Cays. Station in Main Channel: A) Cast 871110/1a in side view, 1 specimen of Alpheus floridanus entombed; B) Cast 871110/2 in side view, pair of Alpheus floridanus entombed. "Cassiopea Cove": C) Burrow opening of an A. floridanus associated with a gobiid fish; D) Cast 871031/E in side view, 1 specimen of A. heterochaelis entombed; E) Cast 871103/1, burrow of A. floridanus associated with a gobiid fish. (Scale $10 \mathrm{~cm}$ in A, B, D, and E; $1 \mathrm{~cm}$ in C; arrows show positions where animals were entombed). 

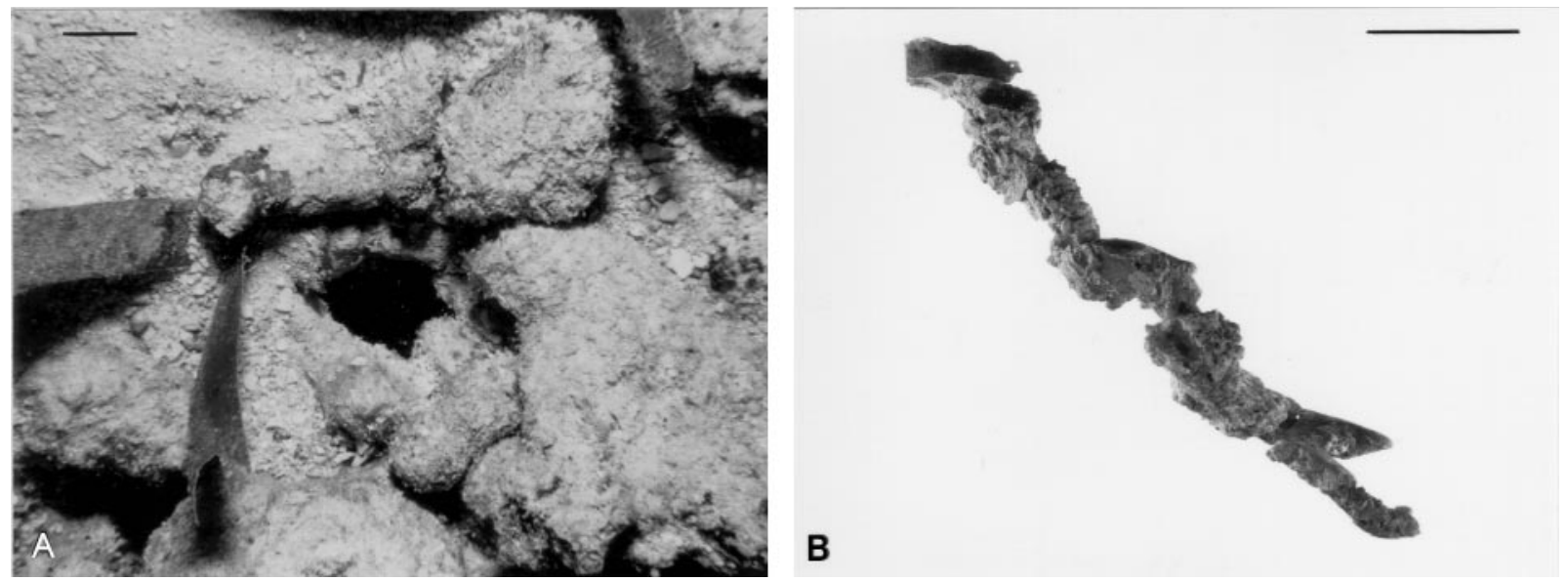

Fig. 4. A) Burrow opening of Axiopsis serratifrons, Carrie Bow Cay near "Garbage Reef" (scale $1 \mathrm{~cm}$ ); B) Resin cast of an A. serratifrons burrow, North End Sand Bar (scale $10 \mathrm{~cm}$ ).

present in lower burrow parts. A second cast made in 1989 with epoxy has a smaller vertical extension and is more branched. The burrow wall is not lined, allowing the epoxy to penetrate into the interstices of the coral rubble. The shrimp have a total length between 33 and $46 \mathrm{~mm}$ and live in pairs; in one case a pair inhabited a burrow continuing in an empty, buried conch shell.

In the laboratory, A. serratifrons immediately begins constructing a new burrow. Small sediment particles (sand) are carried in the basket formed by the first two pair of pereiopods. The animal is able to carry pieces of coral rubble even larger than itself. In the initial phase of reburrowing, sediment and pieces of coral rubble are transported onto the sediment surface. Later, coral rubble removed from deeper sediment layers is placed on upper parts of the burrow and vibrated until firmly positioned. Spaces between larger particles are filled with smaller ones, thus preventing sand from shifting into the deeper burrow parts. Within 24 hours a simple burrow had been constructed. One female moulted in the aquarium and changed color from black to bright red. She became darker within a few days. The exuvia was buried.

\section{Corallianassa longiventris (A. Milne Edwards)}

This shrimp occurs around Carrie Bow Cay both in coral rubble and coarse sand in shallow water (0 to $1.5 \mathrm{~m}$ ). The burrow opening is a circular hole with smooth edges, 0.4 to $3 \mathrm{~cm}$ in diameter; the brightly colored shrimp can often be seen at the opening, especially at night. The animal can be baited with seagrass, which it tries to pull into its burrow (Fig. 5 C). At night, the shrimp were occasionally observed to jump nearly completely out of their burrows while catching floating seagrass. In 1989, the openings were often blocked during daytime. Several small burrows of this shrimp were casted near North End Sandbar in May 1988 (Figs. 5 A and B).They all have a J-shaped, slightly spiral shaft with uniform circular cross-section (diameter between 4.7 and $10.5 \mathrm{~mm}$ ). A typical, wider (10 - $15 \mathrm{~mm}$ in diameter), short horizontal chamber is present at a sediment depth between 12 and $35 \mathrm{~cm}$. A second, similar chamber is present in all casts at a depth between 20 and $60 \mathrm{~cm}$. Four casts show a third, two a fourth and a fifth chamber along the vertical part of the burrow. Between 40 and $60 \mathrm{~cm}$ the burrow turns horizontally and gives rise to several short $(2$ to $3 \mathrm{~cm}$ ) bifurcated tunnels. These tunnels end blindly and are filled with coarse sediment and seagrass blades (Fig. 5 D). The depth of subsequent chambers along the shaft as well as total depth $(42$ to $83 \mathrm{~cm})$ is correlated with mean burrow diameter. Only one cast (Fig. 5 A) shows a shaft branching off at a sediment depth of 53 $\mathrm{cm}$ and leading to the surface (resulting in a Y-shape). All casts are obviously incomplete because they either broke off at their deepest part due to the hard substrate or were blocked with sediment by the animal. The burrow wall in most parts is smooth and lined; even in situ the fine light brown material lining the wall at the opening contrasts with the surrounding white sediment.

\section{Neocallichirus grandimana (Gibbes)}

This species inhabits the lagoonside of South Water Cay from the intertidal to $0.7 \mathrm{~m}$ water depth in coarse sand. A total of 11 specimens was collected in June 1989 using a yabby pump. Their measurements are summarized in Table 1.

Burrow openings occur in densities between 12 and 36 holes $\cdot \mathrm{m}^{-2}$; they vary in appearance from simple holes (diameter 0.5 to $1 \mathrm{~cm}$ ) to small funnels (diameter $=2-3 \mathrm{~cm}$ 

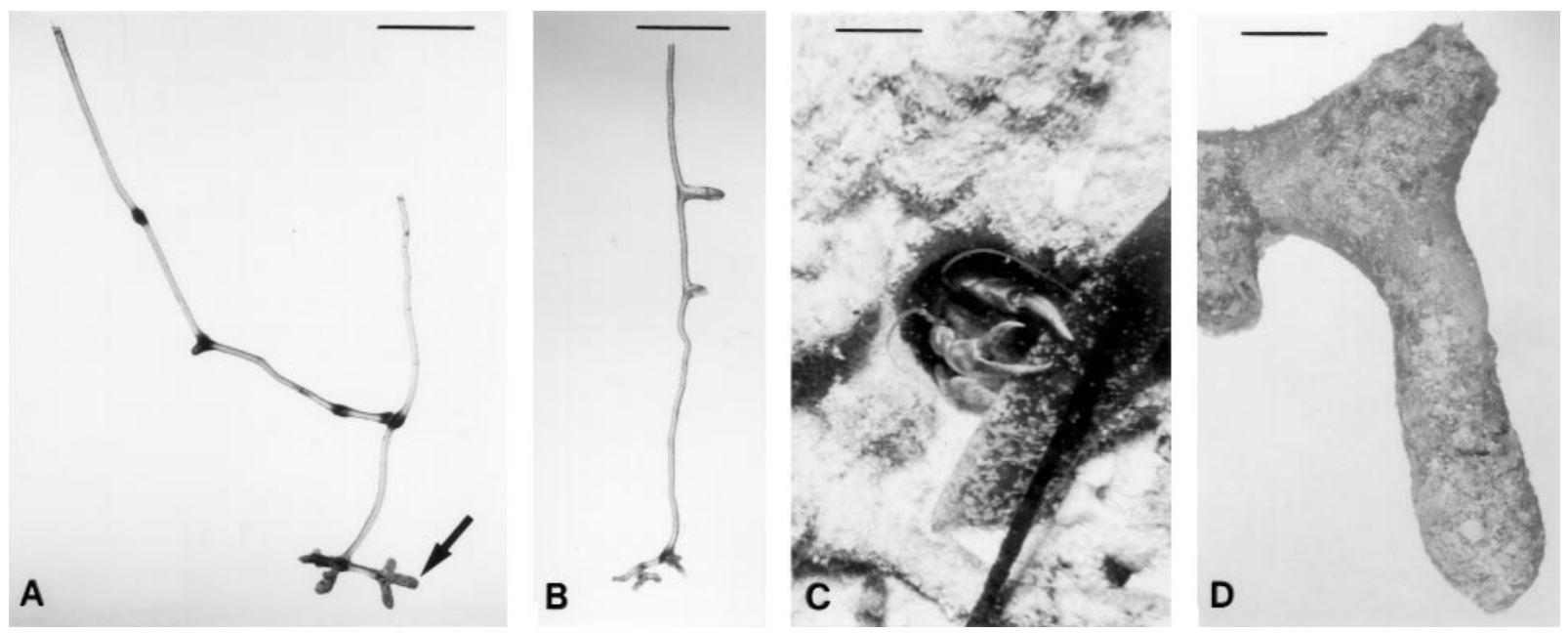

Fig. 5. Corallianassa longiventris, Carrie Bow Cay. A) Resin cast $8805 / 2$ in side view; B) Resin cast $8805 / 4$ in side view, North End Sand Bar; C) Animal trying to pull seagrass into its burrow, South End; D) Detail of deep chamber (arrow in A) showing seagrass debris (scale $10 \mathrm{~cm}$ in $\mathrm{A}$ and $\mathrm{B}, 1 \mathrm{~cm}$ in $\mathrm{C}$ and $\mathrm{D}$ ).

near the surface) or small mounds ( 2 to $3 \mathrm{~cm}$ high and 10 to $15 \mathrm{~cm}$ in diameter at their base)(Fig. $6 \mathrm{~A}$ ).

Five incomplete and 2 nearly complete resin casts (Figs.6 B and C) show that the burrows consist of a vertical shaft with a circular cross-section $(10-15 \mathrm{~mm}$ in diameter) leading to a depth between 13 and $16 \mathrm{~cm}$. The burrow then widens and turns into the main part, which is mainly horizontal. Total depth ranges from 28 to 36 $\mathrm{cm}$. The burrow cross-section is circular in interconnecting segments (diameter 21-23.5 mm), with wider (diameter $32-41.5 \mathrm{~mm}$ ) branchings at an angle of $120^{\circ}$. As judged from casts the burrow wall is rough; digging and yabby pump samples show that it is partly plastered with fine-grained brown sediment as opposed to the whitish surrounding sediment.

In the laboratory, N. grandimana was a rapid burrower and completed a simple burrow within 1 hour.

\section{Glypturus acanthochirus Stimpson}

The most characteristic features of the burrowing activity of this shrimp are numerous mounds and funnels (Fig. 2 A). In Cassiopea Cove, mounds occur in a density of up to $3 \cdot \mathrm{m}^{-2}$, are $12-30 \mathrm{~cm}$ high and have a

Table 1. Measurements (in mm) of Neocallichirus grandimana specimens collected at South Water Cay with the yabby pump;

\begin{tabular}{lllllccccc} 
date & sex & TL & CL & si & PLma & PWma & PLmi & PWmi & Museum \\
\hline 890610 & $\mathrm{~m}$ & 49 & 16.0 & $\mathrm{r}$ & 11.0 & 10.0 & 7.0 & 4.8 & NHMW \\
890610 & $\mathrm{f}$ & 77 & 23.4 & 1 & & & 8.2 & 5.2 & NHMW \\
890610 & $\mathrm{~m}$ & 45 & 12.2 & $\mathrm{r}$ & 7.0 & 7.0 & 4.6 & 3.2 & MP \\
890610 & $\mathrm{~m}$ & 46 & 15.0 & $\mathrm{r}$ & 11.0 & 9.6 & 5.2 & 4.6 & NHMW \\
890610 & $\mathrm{~m}$ & 36 & 11.8 & $\mathrm{r}$ & 8.2 & 7.0 & 4.4 & 3.2 & NHMW \\
890610 & $\mathrm{fo}$ & 82 & 23.2 & 1 & 15.2 & 13.6 & & & NHMW \\
890610 & $\mathrm{dc}$ & & & $\mathrm{r}$ & 14.4 & 13.8 & & & \\
890610 & $\mathrm{dc}$ & & & 1 & 11.0 & 10.8 & & & NHMW \\
890613 & $\mathrm{~m}$ & 52 & 16.2 & 1 & 8.0 & 7.6 & 5.0 & 4.0 & NHMW \\
890613 & $\mathrm{~m}$ & 62 & 18.6 & 1 & 16.0 & 13.0 & 8.0 & 5.6 & MP \\
890613 & $\mathrm{f}$ & 51 & 14.2 & 1 & 10.6 & 9.4 & 5.0 & 3.6 & \\
890613 & $\mathrm{dc}$ & & & 1 & 13.2 & 13.0 & & & MP \\
890626 & $\mathrm{~m}$ & 51 & 20.6 & 1 & 15.0 & 14.6 & 6.8 & 5.2 & entombed \\
890626 & $?$ & 80 & & $\mathrm{r}$ & & & & & \\
\hline
\end{tabular}

Sex, f: female, fo: ovigerous female, m: male, dc: detached cheliped; TL: total length; CL: carapace length; si: side of major cheliped, r: right, 1 : left; PLma: length of major cheliped; PWma: width of major cheliped; PLmi: length of minor cheliped; PWmi: width of minor cheliped; Museum in which specimens have been deposited (NHMW: Naturhistorisches Museum Wien; MP: Muséum National d'Histoire Naturelle Paris). 

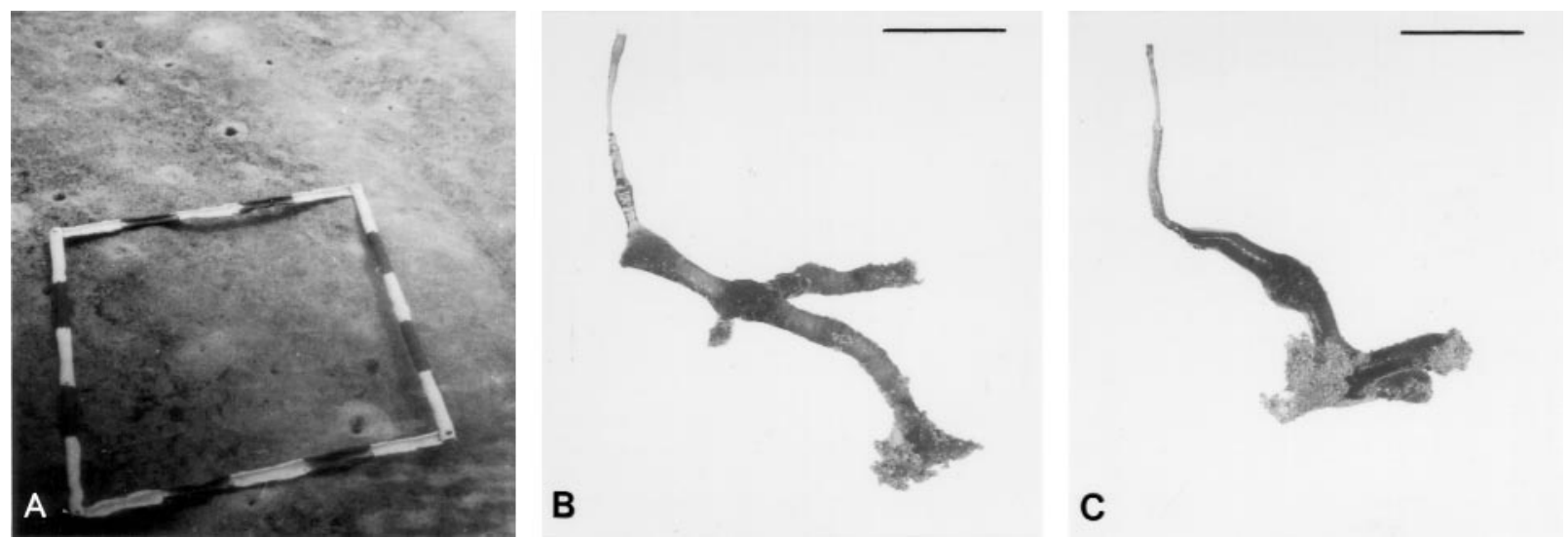

Fig. 6. Neocallichirus grandimana, South Water Cay. A) Burrow openings (frame $=50 \times 50 \mathrm{~cm}$ ); B) Cast SWC3 in side view; C) Cast SWC4a in side view (scale $10 \mathrm{~cm}$ ).

diameter of $30-50 \mathrm{~cm}$ at their base. The mounds are topped either by a small hole (1-2 $\mathrm{cm}$ in diameter) or a crater (3-5 $\mathrm{cm}$ in diameter). Funnels occur in densities of up to $5 \cdot \mathrm{m}^{-2}$, vary in size from small $(4-5 \mathrm{~cm}$ in diameter, 10 to $15 \mathrm{~cm}$ deep) to large craters $(30-50 \mathrm{~cm}$ in diameter at the surface, up to $30 \mathrm{~cm}$ deep). In most cases a sharp-edged hole (2-3 cm in diameter) is visible at the base of the funnel. Sediment often slides in form of an avalanche from one mound into an adjoining funnel (Fig. 2 A).

Two nearly complete (Fig. 7) and several incomplete resin casts show the following general pattern for $G$. acanthochirus burrows: One opening is situated at the base of the funnel. A tunnel (40 to $70 \mathrm{~cm}$ long, dip angle between 15 and $40^{\circ}$ ) leads to a central gallery in a depth between 15 to $50 \mathrm{~cm}$. This tunnel is always constricted due to shell or coral fragments; its cross-section is elliptical just below the entrance and circular (24 $-27 \mathrm{~mm}$ in diameter) near the central gallery. Here, in the first floor, several tunnels with circular cross-sections branch off the main central part, which continues deeper as a spiral main shaft. In one cast (Figs. $7 \mathrm{~A}$ and B), 6 of the radiating branches become constricted 20 to $30 \mathrm{~cm}$ from the central gallery and lead as thin, flat tunnels towards the sediment surface where they end blindly, one of them at the base of a mound. These constrictions are again due to larger particles such as shells and coral rubble (Fig. 7 D). In the second complete cast (Fig. $7 \mathrm{E}$ ), only one tunnel (dip angle $40^{\circ}$ ) leads towards the surface; it ends - after branching (not cast) - at the base of two mounds. In the first complete cast (Fig. 7 A) and most of the incomplete ones, one to two curved, 10 to 30 $\mathrm{cm}$ long tunnels, branch off the central gallery. These become wider distally ( $30 \mathrm{~mm}$ in diameter) and end blindly. At greater depth, additional tunnels branch off the main shaft. Some of these blind tunnels are rounded distally, others show a typical constriction followed by a tunnel densely packed with large shells, mainly of Bulla and Chione
(Fig. 7 C). In the second complete cast these branches are much wider distally, forming chambers whose bottoms are filled with Halimeda chips and seagrassdebris. Up to six levels of chambers or tunnels branching off the main shaft may be present. The total depth of the burrows ranges between 73 and $160 \mathrm{~cm}$. In the second complete cast (Fig. 7 E) a shaft (dip angle $70^{\circ}$ ) leads straight from the deepest point to the surface. Along this shaft one tunnel (constricted, filled with shells) and two short chambers (filled with seagrass) are present at sediment depths of 117 and $92 \mathrm{~cm}$, respectively. This shaft could be cast only because a hole opened near the opening in the funnel due to the response of the animal to the incoming resin.

The burrow wall is smooth and lined; the sticky lining is responsible for the compactness of the deeper sediment layers. Mounds have no open connection to the underlying burrow although they sometimes show holes on top. They may also be surrounded by faecal pellets. They consist of soft sediment with an aggregation of small shell particles and Halimeda chips inside their base. Grain size analysis shows that the sediment at the base of the mounds contains more coarse material than ambient sediment; the sediment around the burrow wall, on the other hand, has a higher fraction of fine particles (Fig. 8).

Due to the great burrow depth and sticky sediment, this shrimp can only be captured by means of the weighted line (Vaugelas, 1984). In 1989, 39 trials using 11 traps over 16 days resulted in seven successful captures. In these cases, holes into which the line was introduced became filled overnight, the line was straight and the entangled animals could be dug out carefully by hand. The measurements of the 14 specimens collected with this method in 1987 and 1989 are summarized in Table 2.

In the Main Channel south of Cassiopea Cove, the number of mounds and funnels decreases with increasing 

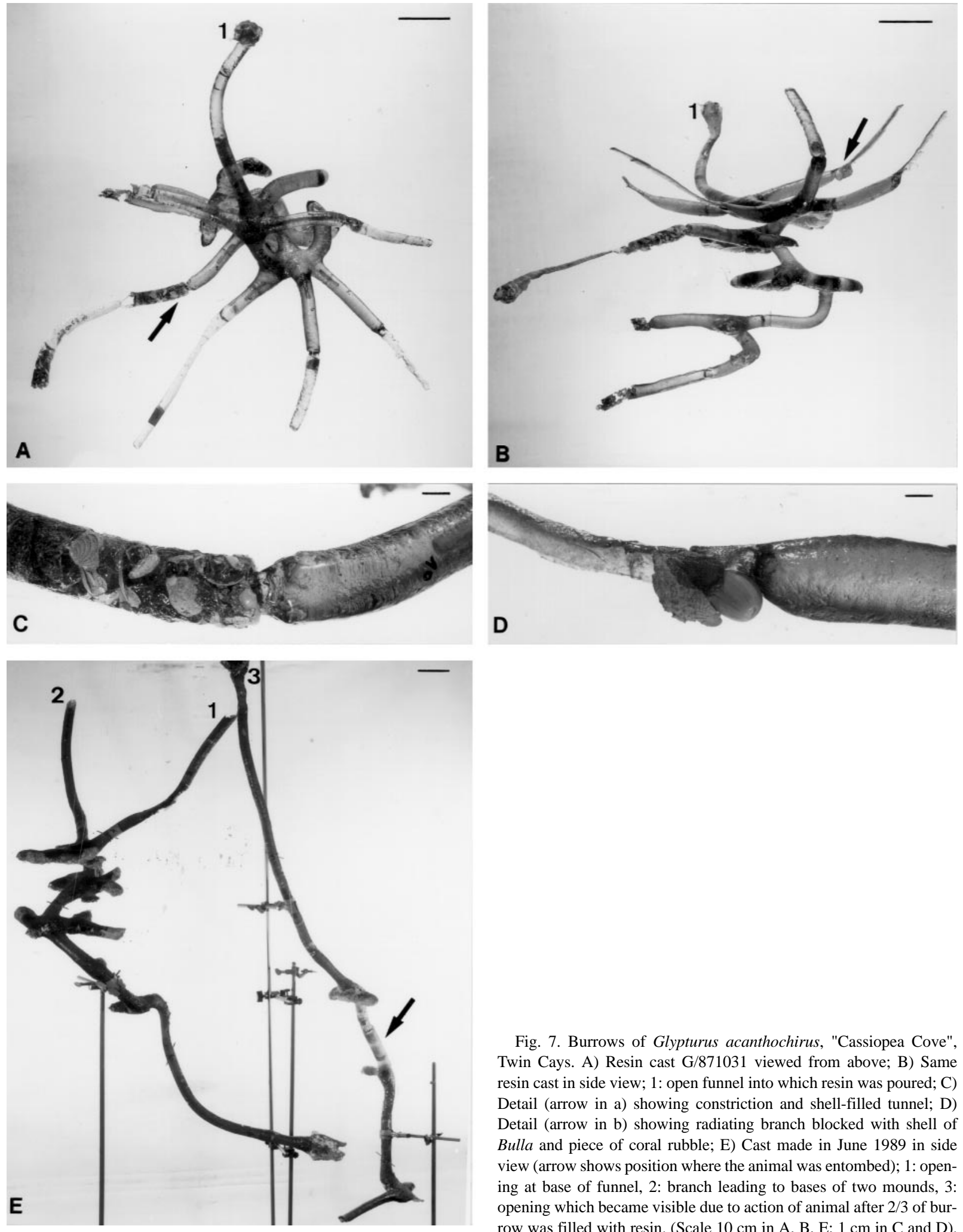

Fig. 7. Burrows of Glypturus acanthochirus, "Cassiopea Cove", Twin Cays. A) Resin cast G/871031 viewed from above; B) Same resin cast in side view; 1: open funnel into which resin was poured; $C$ ) Detail (arrow in a) showing constriction and shell-filled tunnel; D) Detail (arrow in b) showing radiating branch blocked with shell of Bulla and piece of coral rubble; E) Cast made in June 1989 in side view (arrow shows position where the animal was entombed); 1: opening at base of funnel, 2: branch leading to bases of two mounds, 3 : opening which became visible due to action of animal after $2 / 3$ of burrow was filled with resin. (Scale $10 \mathrm{~cm}$ in $\mathrm{A}, \mathrm{B}, \mathrm{E} ; 1 \mathrm{~cm}$ in C and D). 


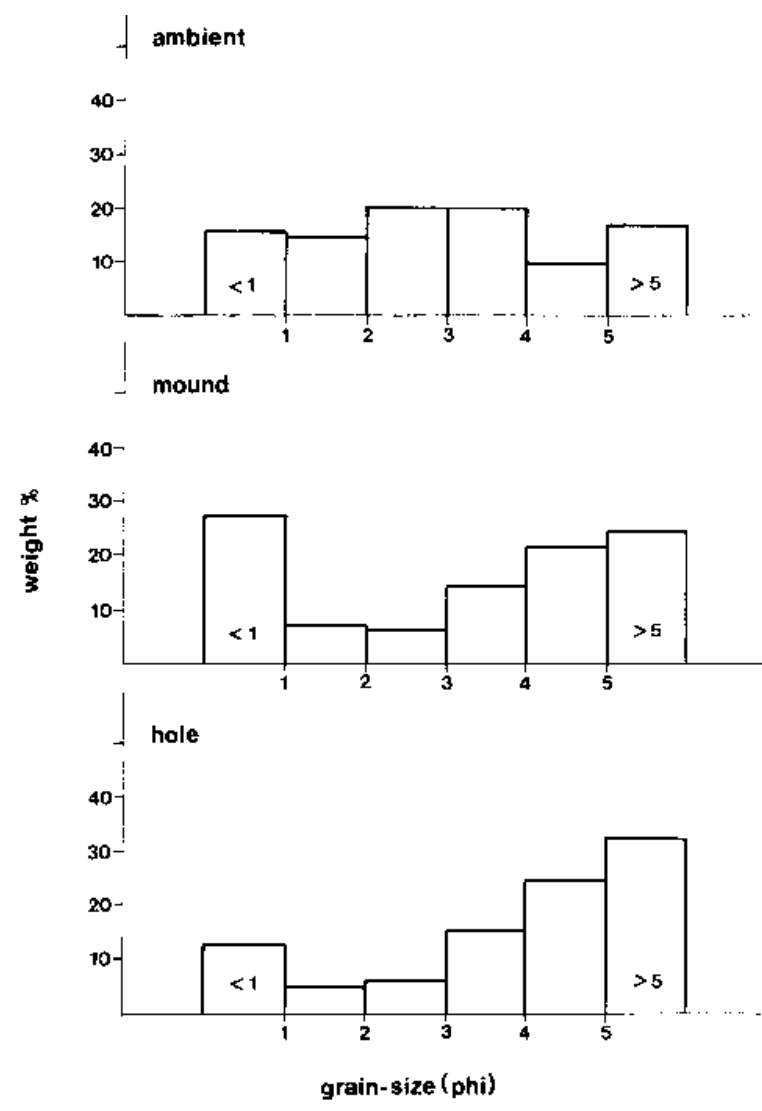

Fig. 8. Grain size distribution of sediments at different locations of a Glypturus acanthochirus burrow, Twin Cays, Belize; ambient: sediment between mounds; mound: sediment from the top down to the base of the mound; hole: sediment surrounding the opening in the funnel down to a depth of $10 \mathrm{~cm}$.

density of Thalassia. At station 2, only few mounds are present in the middle of the Channel in approximately 3 to $5 \mathrm{~m}$ depth.

At the Main Channel entrance (station 3) only small mounds occur (base diameter 5 to $10 \mathrm{~cm}$ ) at densities between 1 and $3 \cdot \mathrm{m}^{-2}$; they are occasionally surrounded by fecal pellets. Small depressions nearby, often obscured by larger shell particles, show a hole $(1.5$ to $2.5 \mathrm{~cm}$ in diameter) which is smooth-edged and lined. Density ranges between 1 and 3 funnels $\cdot \mathrm{m}^{-2}$. Weighted lines and resin casting failed to capture any animals. The burrows were blocked by shells and coral rubble. Digging in the firm sand indicated a burrow shape similar to that of the casts made in Cassiopea Cove.

At South Water Cay, G. acanthochirus is common in bare sands in the shallow subtidal $(0.5$ to $2 \mathrm{~m})$. Mounds occur at densities of up to $22 \cdot \mathrm{m}^{-2}$. The mounds differ from those in Cassiopea Cove in having small open holes on top which may be extended in the form of a chimney.
The holes in the center of the adjoining funnels have a smooth edge and are lined. Funnels occur in densities of up to $8 \cdot \mathrm{m}^{-2}$. Avalanches of sediment from mounds into funnels are more frequent than in Cassiopea Cove and shifting sediment disappearing into holes can be observed in situ. Weighted line traps yielded two complete specimens and one detached cheliped in 1987. Attempts to make resin casts at this site failed due to sediment blocking the burrow entrances in the funnels.

In the laboratory, G. acanthochirus made only feeble attempts to construct a new burrow. Within one week one specimen created only a depression and a mound.

\section{Discussion}

\section{Comparison with previously described burrows}

\section{Alpheus floridanus and A. heterochaelis}

Alpheus floridanus burrows have been described by Shinn (1968) in intertidal areas of Florida and the Bahamas. He observed paired openings, $1.25 \mathrm{~cm}$ in diameter, $5-10 \mathrm{~cm}$ apart, and surrounded by a "lag deposit" of shells. His cast shows a very complex burrow reaching a total depth of $90 \mathrm{~cm}$. Shinn further mentioned that the roofs of the burrow are irregular whereas the floors show a flat surface.

Alpheus heterochaelis burrows have been studied in Georgia estuaries in upper creek bank systems of salt marshes (Bromley and Frey, 1974; Howard and Frey, 1975; Basan and Frey, 1977). They are described as dense, closely integrated networks of interconnected branches in the upper part and a central trunk leading down to a depth of $1 \mathrm{~m}$. The roofs are more irregular than the floors, and the burrows are inhabited by several animals.

Burrows of both A. floridanus and A. heterochaelis in the sublittoral of the Twin Cays mangrove channels are simpler and less deep than those of conspecifics from the intertidal. This supports Frey and Howard's (1975) assumption that $A$. heterochaelis burrows penetrate less deeply into the sediment in the subtidal than in the intertidal.

Both A. floridanus and A. heterochaelis have been reported to live at least in pairs in their burrows (Shinn, 1968; Howard and Frey, 1975; Basan and Frey, 1977). Nolan and Salmon (1970) reported that A. heterochaelis were most often $(65 \%)$ collected in heterosexual pairs. This also seems to be the case in the alpheids at Twin Cays' mangrove channels: several casts showed a pair of entombed shrimp. In addition, some $A$. floridanus are associated with a gobiid fish. This partnership was described for the first time from Florida (Longley and Hildebrand, 1941 as cited in Karplus, 1987). Karplus (1987) reviewed 
Table 2. Measurements (in mm) of Glypturus acanthochirus specimens collected with weighted lines.

\begin{tabular}{|c|c|c|c|c|c|c|c|c|c|}
\hline date & $\operatorname{sex}$ & $\mathrm{TL}$ & CL & si & PLma & PWma & PLmi & loc & Museum \\
\hline 871108 & $\mathrm{f}$ & 102 & 26.7 & 1 & 13.8 & 14.5 & 8.3 & $\mathrm{TC}$ & \\
\hline 871112 & $\mathrm{~m}$ & 105 & 29.0 & 1 & 21.2 & 21.0 & 11.3 & $\mathrm{TC}$ & \\
\hline 871112 & $\mathrm{~m}$ & 92 & 26.5 & $\mathrm{r}$ & 19.9 & 19.0 & 9.8 & $\mathrm{TC}$ & MP \\
\hline 871115 & $\mathrm{~m}$ & 95 & 27.4 & 1 & 19.1 & 19.1 & 11.0 & TC & NMNH \\
\hline 871116 & $\mathrm{~m}$ & 87 & 26.6 & 1 & 20.0 & 18.1 & 10.5 & $\mathrm{TC}$ & NMNH \\
\hline 871117 & $\mathrm{dc}$ & & & $\mathrm{r}$ & 9.1 & 9.6 & & SWC & \\
\hline 871119 & $\mathrm{dc}$ & & & 1 & 12.7 & 14.0 & & $\mathrm{TC}$ & \\
\hline 871118 & $\mathrm{f}$ & 81 & 23.3 & $r$ & 15.5 & 15.4 & 7.8 & SWC & NMNH \\
\hline 871120 & $\mathrm{f}$ & 77 & 22.1 & 1 & 12.7 & 14.4 & & SWC & NHMW \\
\hline 890609 & f & dam & 28.0 & 1 & 15.8 & 15.9 & 9.9 & $\mathrm{TC}$ & NHMW \\
\hline 890609 & $\mathrm{f}$ & 134 & 28.3 & 1 & 18.2 & 17.8 & 11.2 & $\mathrm{TC}$ & NMNH \\
\hline 890609 & $\mathrm{f}$ & 129 & 28.3 & 1 & & & 10.6 & $\mathrm{TC}$ & NHMW \\
\hline 890610 & fo & 126 & 27.0 & 1 & & & 9.8 & $\mathrm{TC}$ & NHMW \\
\hline 890611 & $\mathrm{dc}$ & & & 1 & 16.6 & 16.8 & & $\mathrm{TC}$ & \\
\hline 890613 & $\mathrm{f}$ & 132 & 29.0 & 1 & 8.1 & 17.6 & 10.7 & $\mathrm{TC}$ & MP \\
\hline 890617 & $\mathrm{dc}$ & & & 1 & 17.1 & 17.6 & & $\mathrm{TC}$ & \\
\hline 890621 & $\mathrm{~m}$ & 131 & 30.5 & 1 & 23.7 & 20.3 & 12.2 & $\mathrm{TC}$ & NHMW \\
\hline 890623 & $\mathrm{f}$ & 130 & 29.5 & $\mathrm{r}$ & 16.7 & 16.0 & 10.6 & $\mathrm{TC}$ & NHMW \\
\hline
\end{tabular}

Sex, f: female,fo: ovigerous female, m: male, dc: detached cheliped; TL: total length; CL: carapace length; si: side of major cheliped, r: right, 1: left; PLma: length of major cheliped; PWma: width of major cheliped; PLmi: length of minor cheliped; location (loc), TC: Twin Cays, "Cassiopea Cove", SWC: South Water Cay; Museum in which specimens have been deposited (NHMW: Naturhistorisches Museum Wien; MP: Muséum National d'Histoire Naturelle Paris; NMNH: National Museum of Natural History Washington, D.C.).

in detail the association between burrowing alpheids and gobiid fish; it occurs frequently in tropical waters. He lists A. floridanus as facultatively associated with the gobies Nes longus and Bathygobius curacao. So far, no association with a gobiid has been observed in A. heterochaelis.

\section{Axiopsis serratifrons}

Kensley (1980) reported A. serratifrons in the backreef areas of Carrie Bow Cay in water depths between 0.5 to $2 \mathrm{~m}$ in densities of one burrow per $5 \mathrm{~m}^{2}$. He observed 2 to 3 visible burrow openings in small depressions. In Curaçao, these openings are always surrounded by pieces of rubble and the burrow may reach a depth of up to $40 \mathrm{~cm}$ (Rodrigues, 1983). The present observations on the burrowing behavior agree with those of Kensley (1980) and Rodrigues (1983). A similar behavior has also been reported in Neaxius vivesi by Berrill (1975).

\section{Corallianassa longiventris}

Biffar (1971), who found this species at the lee side of fringe reefs in Florida, notes that the burrow has one or two (1 $\mathrm{m}$ apart) openings and that the animal is visible at the opening. Suchanek (1985) published a drawing of a cast made at the Virgin Islands and described the burrow briefly as simple, relatively straight and deep. His table specifies a burrow diameter of $30 \mathrm{~mm}$, a total depth of 250 $\mathrm{cm}$ and a distance between openings of more than $200 \mathrm{~cm}$.
The burrow is permanent, with some of the openings being blocked off. Suchanek used the burrow of $C$. longiventris to define a new type of burrow representing the feeding mode as "seagrass/algae harvester" based on observations that the species captures drifting seagrass and algae and either incorporate them into the burrow wall or store them in deep chambers. Manning (1987) classified this species as omnivorous based on the fact that it can be baited by mussel flesh. Recently, Griffis \& Suchanek (1991) termed the feeding mode of C. longiventris as "drift catching".

\section{Neocallichirus grandimana}

This species is better known under the name Callianassa branneri (Rathbun). Recently, Manning (1987) showed that it is synonymous with C. grandimana. In a revision of the American Callianassidae by Manning \& Felder (1991) this species has been placed in the genus Neocallichirus Sakai, 1988. The species occurs along the west coast of the Atlantic from Florida in the north to Brazil in the south. Recently, it has been found also at the Pacific coast of Colombia (Lemaitre \& Ramos, 1992). It is common on intertidal flats in Florida, both on protected and wave-washed beaches (Biffar, 1971). The burrows apparently consist of a permanent horizontal part with side branches and one or more narrow vertical parts leading to the surface; the latter change frequently. This change is also indicated by the burrowing behavior 
observed in aquaria. The burrow shape resembles that of Callianassa sp. (Suchanek et al., 1986) from Enewetak atoll.

\section{Glypturus acanthochirus}

G. acanthochirus burrows presented in this paper are very similar to those of Callianassa sp. described by Shinn (1968). The species was later identified as G. acanthochirus (see Biffar, 1971 and personal communication of Shinn in Thompson, 1972). The casts made in Twin Cays, however, are more complete, especially with respect to the radiating branches and the shell-filled deeper tunnels. This may be due to the use of an epoxy resin with a long gelling time instead of a fast polyester. Incomplete casts made by Curran at the Bahamas (personal communication in Vaugelas, 1990) closely resemble the burrows described here and can be attributed to G. acanthochirus. A similar burrow shape have been reported for $G$. laurae (Vaugelas and Saint Laurent, 1984; Vaugelas, 1984, 1990), G. motupore (Poore and Suchanek, 1988; Suchanek personal communication, 1989 and in Vaugelas, 1990) and G. armatus (Vaugelas, personal communication 1987; Vaugelas, 1990). Similar in shape are also the burrows of Callianassa sp. from Aldabra (Farrow, 1971) and Callianassa sp.2 from the Seychelles (Braithwaite \& Talbot, 1972). Both these unidentified species are most probably G. laurae (Vaugelas, 1990).

The presence of a shaft leading from the deepest part of the burrow to the surface is remarkable (second "complete" cast, Fig. 7 E). It is unlikely that such a shaft - if present in all burrows of $G$. acanthochirus or other species of Glypturus - will be filled with resin other than accidentally.

According to Suchanek $(1983,1985)$ G. acanthochirus is a seagrass harvester rather than a deposit feeder; it produces no mounds and can be hand-fed with seagrass. The Twin Cays burrows, however, indicate that G. acanthochirus is a deposit feeder. Sediment falling into the funnel is handled by the animal. Material which is not ingested is transported out of the burrow by ventilation currents and accumulates in form of a mound. Material too large to be transported by ventilation is brought into deeper tunnels, thus forming the typical shell-filled branches. The upper radiating branches may either represent tunnels leading to former or future funnel sites or be "irrigation tunnels" similar to those described by Vaugelas (1987) for C. laurae. Application of the weighted lines showed that the funnel becomes filled within one day when not kept open by the animal. At the site with coarser sediment (South Water Cay) funnels were observed to fill up without any external influence. Material transported out of the mound often slides down into adjacent holes. The firm lining of G. acanthochirus burrow and the relative weak abil- ity of re-burrowing observed in aquaria indicate that the deeper parts are quite permanent.

\section{Distribution of burrows in mangrove and back-reef environments}

The soft subtidal muddy sediments of the mangrove channels are dominated mainly by alpheid shrimps, which inhabit both bare sediments (as in Cassiopea Cove) and those with seagrass cover. In the mangrove channel, Glypturus occurs only in bare mud. The backreef environments show a much higher diversity. Here, (e.g. at South Water Cay) Glypturus inhabits sheltered areas devoid of seagrass cover and reaches a much higher density than in the mangrove channel. Neocallichirus grandimana is restricted to a narrow zone in sheltered sands near the water line. There is a small zone of overlap with Glypturus in the shallow subtidal. The high bioturbation activity of Glypturus probably limits the distribution of $N$. grandimana in the subtidal. Corallianassa can be found in intertidal and subtidal sands with a smaller fine fraction and an increasing amount of coral rubble, while Axiopsis seems to prefer shallow rubble sediments. The distribution of the burrows within the different environments is illustrated in Fig. 9.

\section{Influence of callianassid bioturbation on the environment}

The sediment grain size distribution shows that $G$. acanthochirus influences sediment properties of surface sediments. In addition, very coarse particles are patchily accumulated in deeper burrow parts. Callianassids of reef lagoon environments are known to influence sediment grain size distribution. Suchanek (1983) found that sediment pumped from mounds into collection buckets contained mainly smaller particles $(<1.4 \mathrm{~mm})$, whereas larger particles are stored in deep chambers of the burrows in $C$. rathbunae. Experiments with painted tracer sediment demonstrated that within days smaller particles accumulate at the surface, whereas coarser particles are stored in deeper chambers (30-50 $\mathrm{cm}$ )(Tudhope and Scoffin, 1984; Suchanek et al., 1986). Chambers with coarse particles have also been mentioned in burrows of $G$. armatus from New Caledonia and G. laurae from the Red Sea (Vaugelas, 1990).

Glypturus has a high density only in sediments devoid of seagrass. Whether the absence of seagrass is due to the burrowing activity of the shrimp or whether the seagrass prevents the burrowing remains unclear. Transplantation experiments demonstrate that Callianassa bioturbation negatively influences the health and standing crop of Thalassia, although the root mat may inhibit the invasion by the shrimp (Suchanek 1983). The latter is supported 


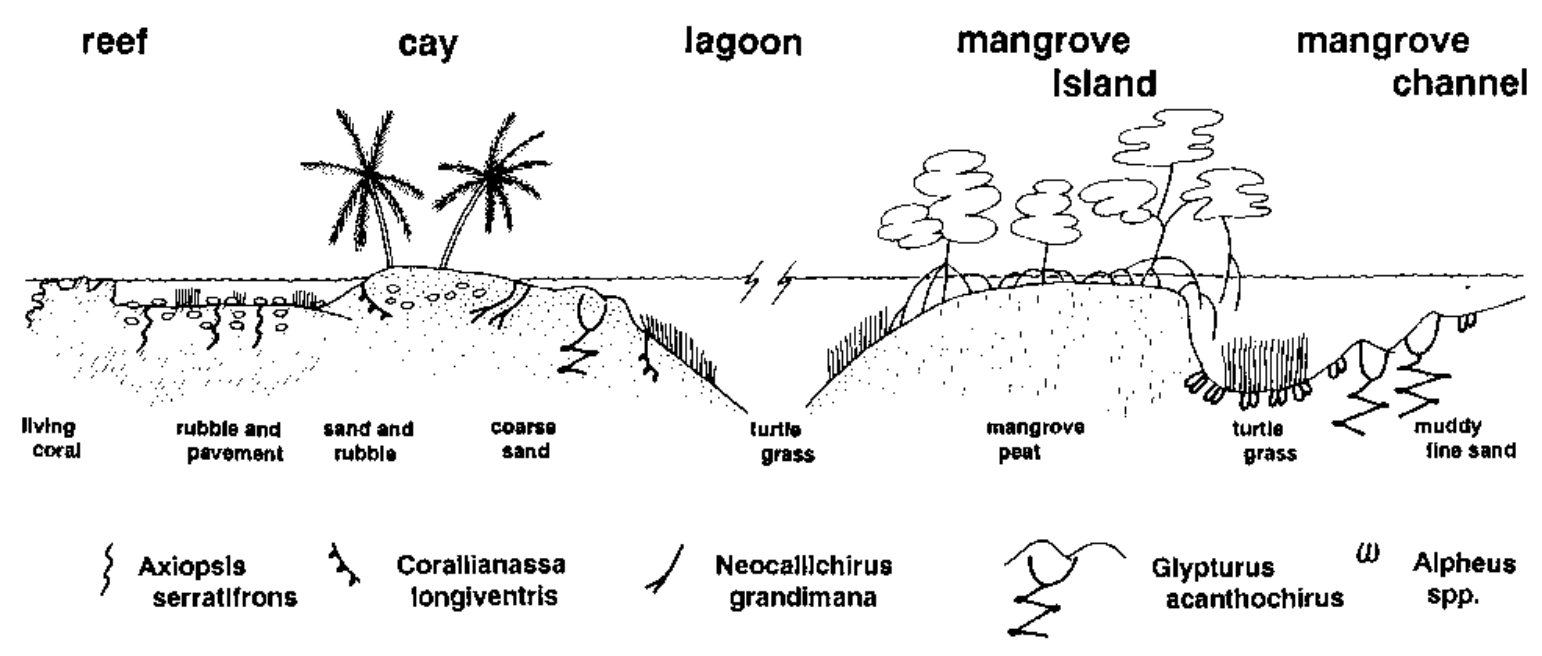

Fig. 9. Schematic burrow distribution in mangrove-channel and back-reef environments at Belize.

by the findings of Harrison (1987): C. californiensis cannot settle in transplanted Zostera japonica.

\section{Burrow morphology and ecology}

Existing classifications of thalassinidean burrows exclusively use ecological criteria to explain construction types. Suchanek (1985) distinguished three different types of burrows in thalassinidean shrimp. According to this classification, burrows of $G$. acanthochirus would fall into type B (deposit or detritus feeders) while both $A$. serratifrons and $C$. longiventris would have to be classified as "seagrass or algae harvesters". The introduction of macrophyte debris, however, seems to be common in thalassinideans; it has also been observed in a number of genera including purported filter feeders such as Upogebia (Frey and Howard, 1975; Ott et al., 1976) or deposit feeders such as Glypturus or Callianassa (Dworschak, 1987). Later, Griffis and Suchanek (1991) updated this classification and defined altogether six burrow types. They distinguished burrows based on the absence or presence of (1) sediment mounds, (2) seagrass in chambers or the burrow lining and (3) a simple "U" shaped burrow design and attribute the types to one of the three general trophic modes (deposit feeding, drift catching and filter/suspension feeding). Absence or presence of mounds is often difficult to distinguish since the persistance of mounds depends on water movement. $N$. grandimana for example cannot be assigned unequivocally to one of these types. Another classification of thalassinidean burrows has been given by Vaugelas (1990). He distinguished four burrow types also mainly based on feeding types and the appearance of opening. He showed an increasing isolation of the shrimps from the surface from the simple type I (omnivorous shrimp which eventually leave the burrow; e.g. A. serratifrons, C. longiventris) to type II (detritivorous, large mounds, e.g. burrows of the genus Glypturus) and type III (mixed suspension and deposit feeders with narrow upper sections and small mounds; e.g.temperate species of Callianassa) to type IV (suspension feeders, e.g. Upogebia). Some species of Upogebia ,e.g. U. pusilla (Dworschak 1987), however, have also been observed feeding on deposited material and even protruding from the burrow similar to $C$. longiventris.

In view of the mixed feeding modes of many thalassinids, it is questionable whether burrow types only reflect feeding types. The highly complex and specific burrows of the Thalassinidea represent characters equivalent to morphological characters used in taxonomy. Burrow shape must be regarded as due to both the phylogenetic affinities and the ecological adaptation of the animal constructing them. Classifications based on feeding mode or sediment type alone reflect a purely adaptationist view, ignoring the historical component.

\section{Acknowledgements}

Financial support was given by Project P5915 of the "Fonds zur Förderung der wissenschaftlichen Forschung in Österreich". This is contribution no. 360, Caribbean Coral Reef Ecosystem (CCRE) Program, Smithsonian Institution, supported by the EXXON Corporation. Our thanks are due to Dr. Klaus Rützler, and to M. Carpenter, Dr. L. Coen, M. Parrish, and L. Sullivan for help during field work.

\section{References}

Alongi, D.M. 1989. The role of soft-bottom communities in tropical mangrove and coral reef ecosystems. Reviews in Aquatic Sciences, 1(2): 243-280. 
Basan, P.B., and Frey, R.W. 1977. Actual-paleontology and neoichnology of salt marshes near Sapelo Island, Georgia. In Crimes, T.P., and Harper, J.C. (eds.), Trace fossils 2. Gological Journal, Special Issue 9: 41-70.

Berril, M. 1975. The burrowing, aggressive and early larval behaviour of Neaxius vivesi (Bouvier)(Decapoda, Thalassinidea). Crustaceana, 29: 92-98.

Biffar, T.A. 1971. The genus Callianassa (Crustacea, Decapoda, Thalassinidea) in South Florida, with keys to the Western Atlantic species. Bulletin of Marine Science, 21(3): 637-715.

Braithwaite, C.J.R., and Talbot, M.R. 1972. Crustacean burrows in the Seychelles, Indian Ocean. Paleogeography Paleoclimatology Paleoecolecology, 11 (4): 265-285.

Buchanan, J.B. 1984. Sediment analysis. In Holme, N.A., and McIntyre, A.D. (eds.), Methods for the study of marine benthos. IBP handbook 16, 2nd edition, Blackwell Scientific Publications, Oxford: 41-65.

Dworschak, P.C. 1987. Feeding behaviour of Upogebia pusilla and Callianassa tyrrhena (Crustacea, Decapoda, Thalassinidea). Investigaciones Pesqueras, 51(Supl.1): 421-429.

Dye, A.H., and Lasiak, T.A. 1986. Microbenthos, meiobenthos and fiddler crabs: trophic interactions in a tropical mangrove sediment. Marine Ecology Progress Series, 32(2-3): 259-264.

Farrow, G.E. 1971. Back-reef and lagoonal environments of Aldabra Atoll distinguished by their crustacean burrows. Symposia of the Zoological Society, London, 28: 455-500.

Frey, R.W., and Howard, J.D. 1975. Endobenthic adaption of juvenile thalassinidean shrimp. Bulletin of the Geological Society of Denmark, 24: 283-297.

Gerlach, S.A. 1958. Die Mangroveregion tropischer Küsten als Lebensraum. Zeitschrift für Morphologie und Ökologie der Tiere, 46: 636-730.

Griffis, R.B., and Suchanek, T.H. 1991. A model of burrow architecture and trophic modes in thalassinidean shrimp (Decapoda: Thalassinidea). Marine Ecology Progress Series, 79: 171-183.

Harrison, P.G. 1987. Natural expansion and experimental manipulation of seagrass (Zostera sp.) abundance and the response of infaunal invertebrates. Estuarine Coastal and Shelf Science, 24: 799-812.

Herndl, G.J. 1991. Microbial biomass dynamics along a trophic gradient at the Atlantic Barrier Reef off Belize (Central America). Pubblicazioni della Stazione Zoologica di Napoli I: Marine Ecology, 12(1): 41-51.

Howard, J.D., Frey, R.W. 1975. Estuaries of the Georgia Coast, U.S.A.: Sedimentology and biology. II.Regional animal-sediment characteristics of Georgia estuaries. Senckenbergiana maritima, 7: 33-103.

Karplus, I. 1987. The association between gobid fishes and burrowing alpheid shrimps. Oceanography Marine Biology Annual Review, 25: 507-562.

Kensley, B. 1980. Notes on Axiopsis (Axiopsis) serratifrons (A. Milne Edwards)(Crustacea: Decapoda: Thalassinidea). Proceedings of the Biological Society of Washington, 93(4): 1253-1263.

Kjerfve, B., Rützler, K., and Kierspe, G.H. 1982. Tides at Carrie Bow Cay, Belize. In Rützler, K., and Macintyre, I.G. (eds.), The Atlantic barrier reef ecosystem at Carrie Bow Cay, Belize, I. Structure and communities, pp.47-58. Smithsonian Institution Press, Washington, D.C.

Lemaitre, R., and Ramos, G.E. 1992. A collection of Thalassinidea (Crustacea: Decapoda) from the Pacific coast of Colombia, with description of a new species and a checklist of eastern Pacific species. Proceedings of the Biological Society of Washington, 105(2): 343-358.

Macintosh, D.J. 1988. The ecology and physiology of decapods of mangrove swamps. Symposia of the Zoological Society London, 59: 315-341.

Macnae, W. 1968. A general account of the fauna and flora of man- grove swamps and forests in the Indo-West-Pacific region. Advances in Marine Biology, 6: 73-270.

Manning, R.B. 1975. Two methods for collecting decapods in shallow water. Crustaceana, 29: 317-319.

Manning, R.B. 1987. Notes on Western Atlantic Callianassidae (Crustacea: Decapoda: Thalassinidea). Proceedings of the Biological Society of Washington, 100: 386-401.

Manning, R.B., and Felder, D.L. 1991. Revision of the American Callianassidae (Crustacea, Decapoda, Thalassinidea). Proceedings of the Biological Society of Washington, 104(4): 764-792.

Micheli, F., Gherardi, F., and Vannini, M. 1991. Feeding and burrowing ecology of two East African mangrove crabs. Marine Biology, 111: 247-254.

Nolan, B.A., and Salmon, M. 1970. The behavior and ecology of snapping shrimp (Crustacea: Alpheus heterochelis and Alpheus normanni). forma et functio, 2: 289-335.

Ott, J.A., Fuchs, B., Fuchs, R, and Malasek, A. 1976. Observations on the biology of Callianassa stebbingi Borrodaille and Upogebia litoralis Risso and their effect upon the sediment. Senckenbergiana maritima, 8(1/3): 61-79.

Ott, J.A., and Novak, R. 1989. Living at an interface: meiofauna at the oxygen/sulfide boundary of marine sediments. In Ryland, J.S., and Tyler, P.A. (eds.), Reproduction, genetics and distribution of marine organisms, Proceedings of the 23rd European Marine Biology Symposium, pp. 415-422, Olsen \& Olsen, Fredensberg.

Pervesler, P., and Dworschak, P.C. 1985. Burrows of Jaxea nocturna Nardo in the Gulf of Trieste. Senckenbergiana maritima, 17(1/3): 33-53.

Poore, G.C.B., and Suchanek, T.H. 1988. Glypturus motupore, a new callianassid shrimp (Crustacea: Decapoda) from Papua New Guinea with notes on its ecology. Records of the Australian Museum, 40(3): 197-204.

Robertson, A.I. 1986. Leaf-burying crabs: their influence on energy flow and export from mixed mangrove forests (Rhizophora sp.) in northeastern Australia. Journal of Experimental Marine Biology and Ecology, 102(2-3): 237-248.

Robertson, A.I., and Daniel, A. 1989. The influence of crabs on litter processing in high intertidal mangrove forests in tropical Australia. Oecologia, 78(2): 191-198.

Rodrigues, S.de A. 1983. Aspectos da biologia de Thalassinidea do Atlantico tropical Americano. Tese apresentada ao Instituto de Biociencias da Universidade de Sao Paulo como parte dos requisitos para obtencao do Titulo de Livre Docente, $174 \mathrm{p}$.

Rützler, K., and Macintyre, I.G. 1982. The habitat distribution and community structure of the barrier reef complex at Carrie Bow Cay, Belize. In Rützler, K., and Macintyre, I.G. (eds.), The Atlantic barrier reef ecosystem at Carrie Bow Cay, Belize, I. Structure and communities, pp.9-45. Smithsonian Institution Press, Washington, D.C.

Shinn, E.A., 1968. Burrowing in recent lime sediments of Florida and the Bahamas. Journal of Paleontology, 42(4): 879-894.

Sakai, K. 1988. A new genus and five new species of Callianassidae (Crustacea: Decapoda: Thalassinidea) from Northern Australia. Beagle, Records of the Northern Territory Museum of Arts and Sciences, 5: 51-69.

Smith, T.J.III, Boto, K.G., Frusher, S.D., and Giddins, R.L. 1991. Keystone species and mangrove forest dynamics: the influence of burrowing crabs on soil nutrient status and forest productivity. Estuarine, Coastal and Shelf Science, 33: 419-432.

Suchanek, T.H. 1983. Control of seagrass communities and sediment distribution by Callianassa (Crustacea, Thalassinidea) bioturbation. Journal of Marine Research, 41:281-298.

Suchanek, T.H. 1985. Thalassinid shrimp burrows: ecological significance of species-specific architecture. Proceedings of the Fifth International Coral Reef Congress, Papeete, Tahiti, 1985, Vol. 5: 205-210.

Suchanek, T.H., Colin, P.L., McMurtry, G.M., and Suchnanek, C.S. 
1986. Bioturbation and redistribution of sediment radionuclides in Enewetak Atoll lagoon by callianassid shrimp: biological aspects. Bulletin of Marine Science, 38: 144-154.

Thomassin, B., 1978. Soft bottom communities. In D.R. Stoddart, and Johannes R.E. (eds.), Coral reefs: research methods. UNESCO monographs on oceanographic methodology, :263-298.

Thompson, R.K. 1972. Functional morphology of the hind-gut gland of Upogebia pugettensis (Crustacea, Thalassinidea) and its role in burrow construction. PhD-Thesis, University of California, Berkeley, 202 p.

Tudhope, A.W., and Scoffin, T.P. 1984. The effects of Callianassa bioturbation on the preservation of carbonate grains in Davies Reef Lagoon, Great Barrier Reef, Australia. Journal of Sedimentary Petrology, 54(4): 1091-1096.

Vaugelas, J.de 1985. A new technique for collecting large-sized callianassid mudshrimp (Decapoda, Thalassinidea). Crustaceana, 49(1): 105-109.

Vaugelas, J.de 1984. Preliminary observations on two types of callianassid (Crustacea, Thalassinidea) burrows. Gulf of Aqaba (Red
Sea). In Saad, M.A.H. (ed.), Proceedings of the Symposium on Coral Reef Environments of the Red Sea, Jeddah, Jan.1984: 520-539.

Vaugelas, J.de 1990. Ecologie des Callianasses (Crustacea, Decapoda, Thalassinidea) en milieu récifal Indo-Pacifique. Conséquences du remaniement sédimentaires sur la distribution des matieres humiques, des métaux traces et des radionucléides. Memoire présenté à l'Université de Nice - Sophia Antipolis pour l'obtention du Diplome d'Habilitation à diriger des recherches en sciences. 226 p.

Vaugelas, J.de, and Saint Laurent, M.de 1984. Premières données sur l'écologie de Callichirus laurae de Saint Laurent sp.nov. (Crustacé Décapode Callianassidae): son action bioturbatrice sur les formations sédimentaires du golfe d'Aquaba (Mer Rouge). Comptes Rendus de l'Academie des Sciences, Paris, Séries III - Sciences de la Vie, 298(6): 147-152.

Verwey, J., 1930. Einiges über die Biologie ost-indischer Mangrovekrabben. Treubia, 12(2): 167-261.

Warren, J.H., and Underwood, A.J. 1986. Effects of burrowing crabs on the topography of mangrove swamps in New South Wales. Journal of Experimental Marine Biology and Ecology, 102(2-3): 223-236. 